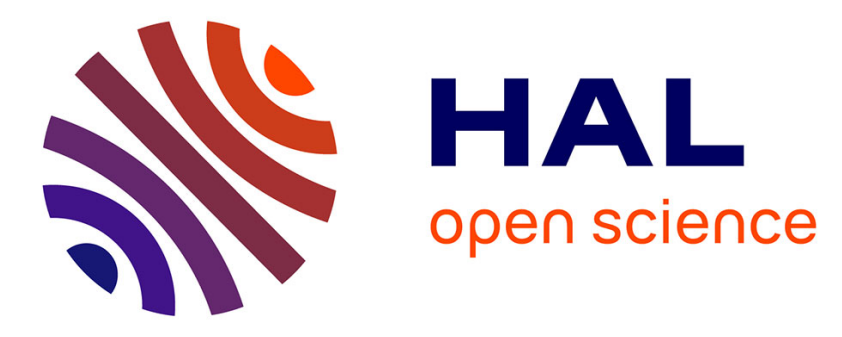

\title{
Double Myod and Igf2 inactivation promotes brown adipose tissue development by increasing Prdm16 expression
}

Maud Borensztein, Say Viengchareun, Didier Montarras, Laurent Journot, Nadine Binart, Marc Lombès, Luisa L. Dandolo

\section{To cite this version:}

Maud Borensztein, Say Viengchareun, Didier Montarras, Laurent Journot, Nadine Binart, et al.. Double Myod and Igf2 inactivation promotes brown adipose tissue development by increasing Prdm16 expression. FASEB Journal, 2012, 26 (11), pp.4584 - 4591. 10.1096/fj.12-208496 . hal-01788739

\section{HAL Id: hal-01788739 \\ https://hal.umontpellier.fr/hal-01788739}

Submitted on 3 Dec 2021

HAL is a multi-disciplinary open access archive for the deposit and dissemination of scientific research documents, whether they are published or not. The documents may come from teaching and research institutions in France or abroad, or from public or private research centers.
L'archive ouverte pluridisciplinaire HAL, est destinée au dépôt et à la diffusion de documents scientifiques de niveau recherche, publiés ou non, émanant des établissements d'enseignement et de recherche français ou étrangers, des laboratoires publics ou privés. 


\title{
Double Myod and Igf2 inactivation promotes brown adipose tissue development by increasing Prdm16 expression
}

\author{
Maud Borensztein, ${ }^{*}, 1$ Say Viengchareun, ${ }^{\dagger}$ Didier Montarras, ${ }^{\ddagger}$ Laurent Journot, ${ }^{\S}$ \\ Nadine Binart, ${ }^{\dagger}$ Marc Lombès, ${ }^{\dagger}$ and Luisa Dandolo ${ }^{*, 2}$ \\ *Genetics and Development Department, Institut National de la Santé et de la Recherche Médicale \\ (INSERM) U567, Centre National de la Recherche Scientifique (CNRS) Unité Mixte de Recherche \\ (UMR) 8104, University of Paris Descartes, Institut Cochin, Paris, France; ${ }^{\dagger}$ INSERM, U693, Faculté \\ de Médecine Paris-Sud, Université Paris-Sud, UMR-S693, Le Kremlin-Bicêtre, France; ${ }^{\ddagger}$ Molecular \\ Genetics of Development Unit, Department of Developmental Biology, Unité de Recherche Associée \\ (URA) CNRS 2578, Institut Pasteur, Paris, France; and ${ }^{\$}$ Institut de Genomique Fonctionnelle, CNRS \\ UMR 5203, INSERM U661, University of Montpellier II, Montpellier, France
}

ABSTRACT Brown fat or brown adipose tissue (BAT), found in newborn mammals as small depots localized in the interscapular region, plays a prominent role in regulating thermogenesis perinatally. The physiological importance of functional BAT has been recently reasserted in human adults. Because myoblasts and adipoblasts emerge from a common mesodermal precursor, we investigated developmental determination and the reciprocal relationship between muscle and adipocyte commitment. Here we show that a mutant mouse defective for both $\operatorname{Ig} 2$ and Myod genes exhibits massive BAT hypertrophy compared with wildtype and single-mutant newborns. The increased adipocyte proliferation in BAT of double-mutant newborns was associated with overexpression of the brown fat-specific marker $U c p 1$. More strikingly, expression of the master key gene Prdm16 involved in the switch between myogenic and brown adipogenic lineages was drastically enhanced. We further demonstrate that concomitant Myod and Igf2 inactivation accelerates differentiation of a brown preadipocyte cell line and induces lipid accumulation and increased Ucp1 and Prdm16 expression. This in vitro approach brings additional support for the implication of both Myod and Igf2 in BAT development. These results provide the first in vivo evidence that a myogenic regulator together with a growth factor act simultaneously but through independent pathways to repress $\operatorname{Prdm16}$, which opens potential therapeutic perspectives for human metabolic disorders.-Borensztein, M., Viengchareun, S., Montarras, D., Journot, L., Binart, N., Lombès, M., Dandolo, L. Double Myod and Igf 2 inactivation promotes brown adipose tissue development by increasing Prdm16 expression. FASEB J. 26, 4584-4591 (2012). www.fasebj.org

Abbreviations: BAT, brown adipose tissue; C/EBP, CCAAT/ enhancer-binding protein; DM, double mutant; E, embryonic day; IRS1, insulin receptor substrate-1; MRF, myogenic regulatory factor; PPAR, peroxisome proliferator-activated receptor; SM, single mutant; UCP1, uncoupling protein-1; WAT, white adipose tissue; WT, wild-type
Key Words: adipogenesis - transcription factors - UCP1 • differentiation

Adipose tissues contain two distinct types of fat, white and brown. White fat cells are associated with chemical storage of energy, whereas brown fat cells dissipate chemical energy in the form of heat. Adipose tissue is of mesodermal origin, as are muscle, bone, and cartilage. Its differentiation is controlled by multiple factors, such as peroxisome proliferator-activated receptor (PPAR) $\gamma 2$, ZFP423, and CCAAT/enhancerbinding protein $(\mathrm{C} / \mathrm{EBP})$, that are adipose-specific genes for both white and brown fat $(1,2)$.

Brown fat or brown adipose tissue (BAT) is found in newborn mice as small depots in the interscapular region. Its development starts around embryonic day 15.5 (E15.5) continues until the end of gestation in rodents. It plays a prominent role in regulating thermogenesis in mammals $(3,4)$. In humans, brown fat is present at birth, but recent evidence has shown that BAT is also present in adults and may play a role in protecting against obesity (5-8).

It was long hypothesized that both white adipose tissue (WAT) and BAT had a common embryonic origin. More recently, it was suggested that in fact white and brown fat cells had distinct origins. Cell fate experiments using the Engrailed-1 (En-1) gene showed that cells expressing this gene in the dermomyotome of the early embryo (E9.5) gave rise not only to some epaxial muscles but also to BAT in the interscapular

\footnotetext{
${ }^{1}$ Current address: Genetics and Developmental Biology Unit, Institut Curie, CNRS UMR3215, INSERM U934, 75005 Paris, France.

${ }^{2}$ Correspondence: Department of Genetics and Development, Institut Cochin, 24 rue Fbg St Jacques, Paris 75014, France. E-mail: luisa.dandolo@inserm.fr

doi: 10.1096/fj.12-208496

This article includes supplemental data. Please visit http:// www.fasebj.org to obtain this information.
} 
dorsal cervical region $(9,10)$. It was then discovered, on differentiation of white and brown preadipocytes from primary cultures, that brown fat cells could express myogenic regulatory factors (MRFs), such as MYOD, MYF5, and MYOGENIN $(7,11)$. Finally, the PRDM16 transcription factor was found to be an essential player in brown adipocyte determination (12). On inactivation of Prdm16, brown adipocytes produce in vitro long fibers expressing myogenic genes, suggesting that this gene could act in a cell autonomous manner to induce a switch between skeletal myoblasts and brown fat cells. In addition, another cell fate experiment has shown that Myf5-expressing cells give rise to both skeletal muscle cells and brown adipocytes in the BAT (13). Taken together, these recent data suggest that muscle and adipocytes share a common embryonic origin. In Myf5-positive progenitors, PRDM16 represses the expression of myogenic genes and induces the differentiation of BAT (14).

PRDM16 plays its regulatory function by binding to the nuclear factors proliferator-activated receptor $\gamma$ coactivator (PGC)- $1 \alpha$ and PGC-1 $\beta$, which then activate genes such as Ppary and C/ebp. BAT is characterized by the expression of the late differentiation marker uncoupling protein-1 (UCP1), a protein responsible for the uncoupling of the respiratory chain in mitochondria of brown adipocytes $(1,15)$.

In our study, we produced a double mutant (DM) lacking both the Igf2 and Myod genes. These mutant mice die at birth of respiratory failure, due to atrophy of their diaphragm (unpublished results). On dissection of the DM E18.5 embryos, we surprisingly discovered an increase in the brown fat mass in the interscapular region. We investigated this phenotype further and compared DMs with single Igf2 and Myod mutants and with wild-type (WT) embryos. Our results show that both Myod and Igf2 genes are required for proper control of BAT development in newborn mice.

To further validate the in vivo results, we performed knockdown experiments of Myod and Igf2 transcripts using a siRNA strategy in a brown preadipose cell line that was induced to differentiate. Double si-Igf2/si-Myod cells showed accelerated differentiation compared with single siRNA-treated cells and control cells. Collectively, our findings reveal an essential role for both the Myod and Igf2 genes via Prdm16 expression in the control of brown adipocyte proliferation and differentiation.

\section{MATERIALS AND METHODS}

\section{Mouse strains}

All experimental procedures are in agreement with guidelines of the animal ethics committee of the Ministère de l'Agriculture (France). Myod ${ }^{-1-}$ mice were bred on a C57BL/6/CBA outbred background and maintained as heterozygous females and males. The $\operatorname{Ig} \mathrm{f}^{-/-}$strain was on a $129 /$ Sv background. Matings between $\mathrm{Myod}^{+/-}$females and Myod $^{+/-} \operatorname{Igf2} 2^{+/-}$males were plugged to collect E18.5 embryos (day of plug E0.5). Offspring genotypes were determined by PCR analysis of tail DNA (Supplemental Table S1).

\section{Embryo collection}

E18.5 embryos were fixed in $4 \%$ paraformaldehyde and embedded in paraffin; $5-\mu \mathrm{m}$ sections were stained with hematoxylin and eosin.

\section{BAT collection}

E18.5 embryos were weighed before dissection of the interscapular mass in the dorsal cervical region. BAT was weighed and snap-frozen in liquid nitrogen.

\section{Cell culture and brown adipocyte differentiation}

T37i cells were cultured as described previously (16). Differentiation into mature brown adipocytes was achieved by treatment with $2 \mathrm{nM}$ triiodothyronine (Sigma-Aldrich, St. Louis MO, USA) and $20 \mathrm{nM}$ insulin (Sigma-Aldrich) for $5 \mathrm{~d}$.

\section{Gene expression analysis}

Total RNA from tissues and cells was extracted with TRIzol (Invitrogen, Carlsbad, CA, USA). Total RNA (1 $\mu \mathrm{g})$ treated with DNase I (Invitrogen) was reverse-transcribed using a High-Capacity cDNA Reverse Transcription kit (Life Technologies, Grand Island, NY, USA). Samples were diluted 10-fold, and $1 / 20$ of the RT reaction was used for quantitative PCR (qPCR) using Fast SYBR Green Master Mix (Life Technologies, Foster City, CA, USA) or using the TaqMan assay for Myod in T37i (probe 4331182; Life Technologies) with 300 $\mathrm{nM}$ concentrations of specific primers (Supplemental Table S1) and performed on a StepOnePlus Real-Time PCR System (Life Technologies). Amplicons of each gene were subcloned into pGEM-T-Easy plasmid (Promega, Madison, WI, USA) and used as standards with serial dilutions spanning 6 orders of magnitude. Data are presented as means $\pm \mathrm{SE}$. The level of gene expression was normalized to the geometric mean of the expression level of $T b p, G a p d h$, and $18 S$ housekeeping genes with geNorm 3.4 software (17).

\section{Gene expression knockdown by siRNA}

T37i cells were seeded at a density of $0.6 \times 10^{5}$ cells in 12-well plates. On the following day, cells were incubated for $3 \mathrm{~h}$ in Opti-MEM serum-free medium (Life Technologies) before transfection with 180 pmol of siRNA using Lipofectamine RNAiMAX (Life Technologies). Stealth Select RNAi sequences for Myod, Igf2, and scramble siRNA (medium GC concentration) are presented in Supplemental Table S1. Cells were cultured for $2 \mathrm{~d}$ before induction of adipocyte differentiation in the presence of insulin and triiodothyronine. Total RNA was extracted at $\mathrm{d} 1$ and $\mathrm{d} 4$. Oil Red $\mathrm{O}$ staining was performed at d 5 .

\section{Oil Red O staining}

Cells were fixed for $1 \mathrm{~h}$ in $10 \%$ buffered formalin and stained for $1 \mathrm{~h}$ with Oil Red O solution $[0.6 \%(\mathrm{w} / \mathrm{v})$ in isopropanolwater $(60: 40)]$. After extensive washing to remove unbound dye, cells were photographed and solubilized in $10 \%$ SDS, and optical density was measured at $520 \mathrm{~nm}$.

\section{Statistical analysis}

Statistical significance of the different experiments was determined using a Kruskal-Wallis test followed by post hoc paired 
comparisons or a Mann-Whitney test, using Prism 5.0 software (GraphPad, San Diego, CA, USA). Results were considered statistically significant at values of $P<0.05$ compared with WT or scramble.

\section{RESULTS}

\section{BAT is increased in Myod $^{-/-} I g 2^{+/-}$DM embryos}

We developed DM mice lacking both Myod and Igf2 genes to analyze their phenotype and their main characteristics. Because Igf2 is imprinted, a paternal heterozygous mouse $\left(\mathrm{Ig} f 2^{\mathrm{mat}^{+} / \mathrm{pat}^{-}}\right)$does not express $\operatorname{Ig} f$. Thus, mating between a heterozygous Myod female $\left(\mathrm{Myod}^{+/-}\right)$and a heterozygous male $\left(\mathrm{Myod}^{+/-} \operatorname{Igf2^{+/-}}\right)$ will produce the 4 genotypes of interest in the same litter: WT, Igf2 $2^{+/-}$mutant, Myod $^{-/-}$mutant, and Myod $^{-/-}$Igf2 $^{+/-}$DM.

On dissection of the embryos, we discovered a strong hypertrophy of the BAT mass in the interscapular region in DM compared with WT or single mutant (SM) newborns. Histological examinations of E18.5 hematoxylin and eosin-stained sections confirmed the BAT enlargement in DM embryos (Fig. 1A). However, a slight increase of BAT in Igf2 $2^{+/}$embryos was also noted compared with that in WT and $\mathrm{Myod}^{-/-}$embryos. The BAT weight of E18.5 embryos of each genotype was compared with their body weight, because the $\operatorname{Igf2^{+/-}}$ and DM embryos are $40 \%$ smaller than the WT or $\mathrm{Myod}^{-/-}$mutants, as reported previously (18).

In WT embryos, whereas interscapular BAT represented $0.9 \%$ of the total body mass (Fig. $1 A$, bottom panel), BAT weight of $I g 2^{+/-}$mutants displayed a significant difference compared with BAT weight of WT and $\mathrm{Myod}^{-/-}$embryos (+25\%). More interestingly, the DM BAT showed a striking increase in weight of $64 \%$ compared with the BAT weight of their WT or Myod $^{-1-}$ littermates. The DM interscapular BAT therefore represented $>1.5 \%$ of the total body mass (Fig. $1 A$, bottom panel). Absence of IGF2 protein therefore induces a weak but significant BAT mass enlargement, yet this was clearly enhanced by the simultaneous deletion of the Myod gene.

To examine whether a compensation for these two genes occurs in BAT, we measured Igf 2 and Myod expression by RT-qPCR in E18.5 WT, Igf2 ${ }^{+/-}$, Myod $^{-/-}$, and DM BAT (Fig. 1B). No obvious difference was observed, either for $I g f 2$ expression in $\mathrm{Myod}^{-/-}$embryos or for Myod expression in $\operatorname{Ig} f 2^{+/-}$embryos. These

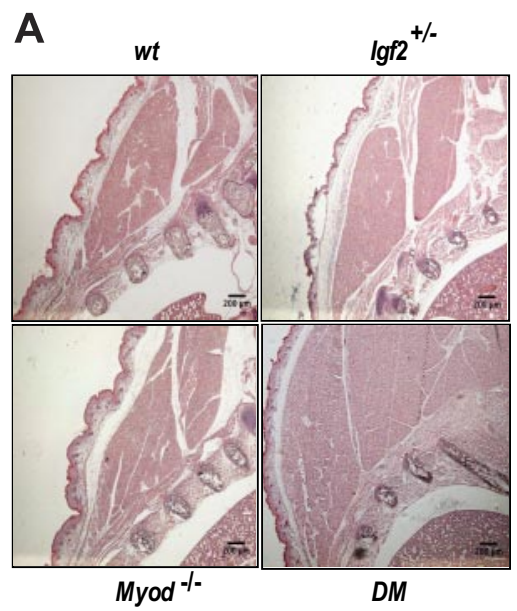

BAT weight

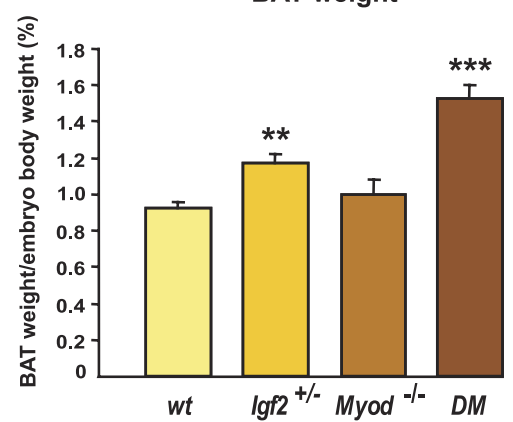

B
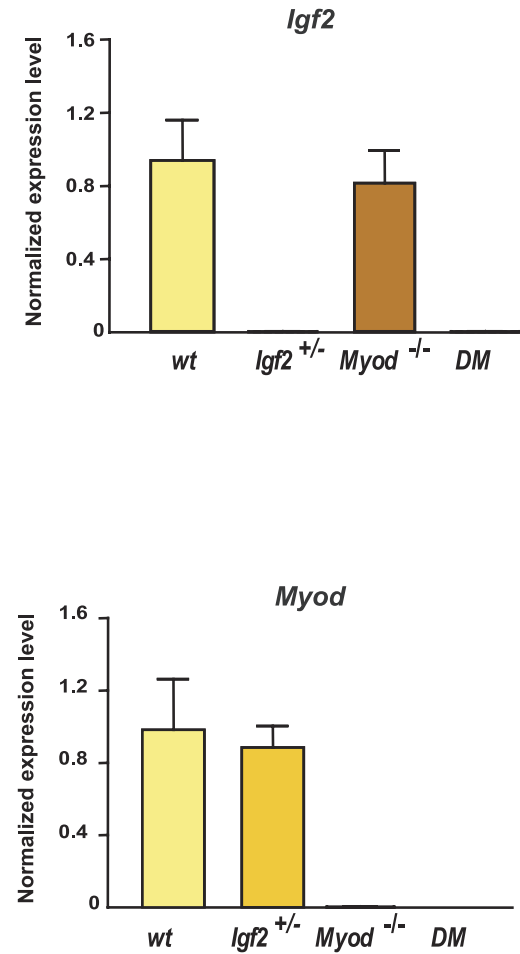

C

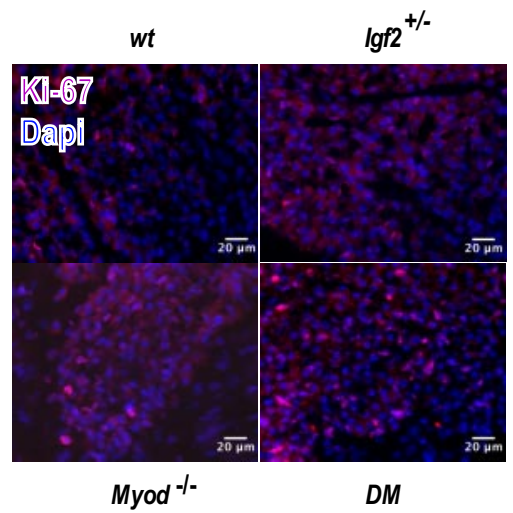

Proliferation index

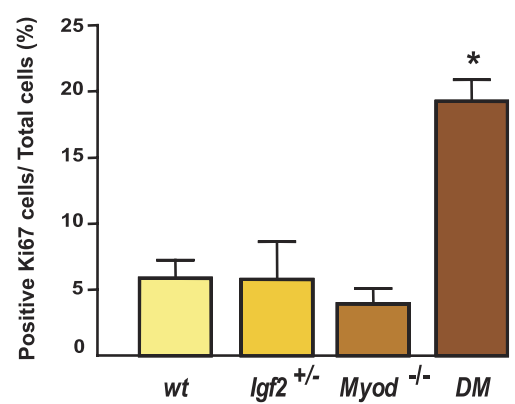

Figure 1. BAT hypertrophy in E18.5 WT and mutants. A) Sections stained with hematoxylin and eosin are shown for WT, Igf2 SM $\left(\operatorname{Igf2} 2^{+/-}\right)$, Myod SM $\left(\operatorname{Myod}^{-/-}\right)$, and DM $\left(\operatorname{Myod}^{-/-} \operatorname{Igf2}^{+/-}\right)$BAT $(n=5 /$ genotype). BAT was dissected from the embryos and weighed. Graph represents the ratio of BAT weight to embryo body weight. Numbers of BAT samples are 20 for WT, 17 for $\operatorname{Igf} 2^{+/-}, 6$ for $\mathrm{Myod}^{-/-}$, and 10 for DM. B) RT-qPCR was performed on E18.5 BAT from WT, SM, and DM mice $(n=5 /$ genotype) using primers for the $\operatorname{Ig} f 2$ gene (top panel) and Myod gene (bottom panel). C) Nuclei of BAT sections stained with antibodies to Ki67 (red) and DAPI (blue) for WT, Igf2 SM, Myod SM, and DM mice ( $n=4$ /genotype). Graph presents the ratio of Ki67-positive cells to total cells. $* P<0.05, * * P<0.01, * * * P<0.001$ vs. WT. 
results indicate a lack of genetic compensation in this tissue.

To evaluate the important BAT hypertrophy in DM embryos, Ki67 labeling was used to assess cell proliferation status in E18.5 embryos (Fig. 1C). The ratio of Ki67-positive nuclei over total cell number showed no difference between WT and SMs. In contrast, in absence of both Myod and Igf2, cell proliferation was increased 4-fold. This high proliferation index thus constitutes a key feature of the DM hypertrophy. The number of adipocytes per field was also evaluated at high magnification and showed no difference among samples (Supplemental Fig. S1). Therefore, the adipocyte size is probably not modified between the different genotypes, suggesting that their number may be greatly increased in the DM embryos. Taken together with the increased mass of the DM BAT, we can conclude that the double knockout of both Myod and Igf2 genes results in hyperplasia of the brown adipocytes.

\section{Expression of MRFs in SM and DM BAT}

It has been well established that the absence of MYOD in skeletal muscle is rescued by overexpression of the other MRFs, especially MYF5 (19, 20). Because a common origin has been proposed for myoblasts and brown adipocytes, we investigated whether such genetic compensation also occurs in BAT. The expression of Myf5, Myogenin, and Mrf4 was evaluated by RT-qPCR in E18.5 BAT from WT, $\operatorname{Igf} 2^{+/-}, \operatorname{Myod}^{-/-}$, and DM mice (Fig. 2). Interestingly, Myf5 and Myogenin genes are overexpressed in the absence of Myod. Surprisingly, this genetic compensation of myogenic regulators in the BAT was not observed in DM mice (Fig. $2 A, B$ ), indicating that IGF2 is required for BAT Myf5 and Myogenin overexpression in Myod $^{-/-}$mice. In sharp contrast, Mrf4 expression was comparable between $\operatorname{Ig} f 2^{+/-}$, Myod $^{-/-}$, and WT newborns, whereas it was significantly down-regulated $(-65 \%)$ in the absence of both Myod and Igf2. This finding suggests that Myod and $I g f 2$ act coordinately according to parallel independent pathways to activate $\mathrm{Mrf4}$.

\section{$\operatorname{Prdm16}$ and $U c p 1$ expression is strongly increased in DM BAT}

To decipher the molecular mechanisms implicated in BAT hypertrophy, we evaluated expression levels of specific markers of BAT differentiation by RT-qPCR on BAT samples. Comparable levels of $C / e b p \beta$ and Ppary 2 were observed in WT, SM, or DM BAT, suggesting that brown adipocyte commitment is not affected in the DM embryos (Fig. 3A, B).

We then focused on the Prdm16 and Ucp1 genes, which are, respectively, early and mature specific brown fat markers. In striking contrast, a 4-fold increase in Prdm16 expression was observed in DM BAT compared with the other genotypes (Fig. 3C). This observation is in accordance with the major role of Prdm16 in the brown adipogenesis pathway. A 3-fold increase of the Ucp1 gene expression was also detected in DM BAT, compared with WT and SM BAT (Fig. 3D). This result confirms that combined expression of both Myod and $I g f 2$ is essential to control BAT proliferation.

\section{Down-regulation of $\operatorname{Myod}$ and Ig 2 transcripts leads to an acceleration in brown preadipocyte differentiation}

To exclude potential systemic counterregulatory mechanisms and to confirm the direct involvement of Myod and $I g f 2$ in the regulation of BAT development, we used the brown adipocyte T37i cell line (16) and knocked down either Myod or Igf2 or both by a siRNA strategy. This cell line is a preadipocyte model for which differentiation into mature brown adipocytes can be triggered by addition of insulin and triiodothyronine. Efficiency of the knockdown of $I g f 2$ and Myod was evaluated by RT-qPCR (Fig. $\mathbf{4 A}, \boldsymbol{B}$ ). At $3 \mathrm{~d}$ after siRNA treatment, a reduction of $\sim 90 \%$ of the $I g f 2$ transcript level in the presence of the si-Igf2 (Fig. $4 A$ ) and $85 \%$ of
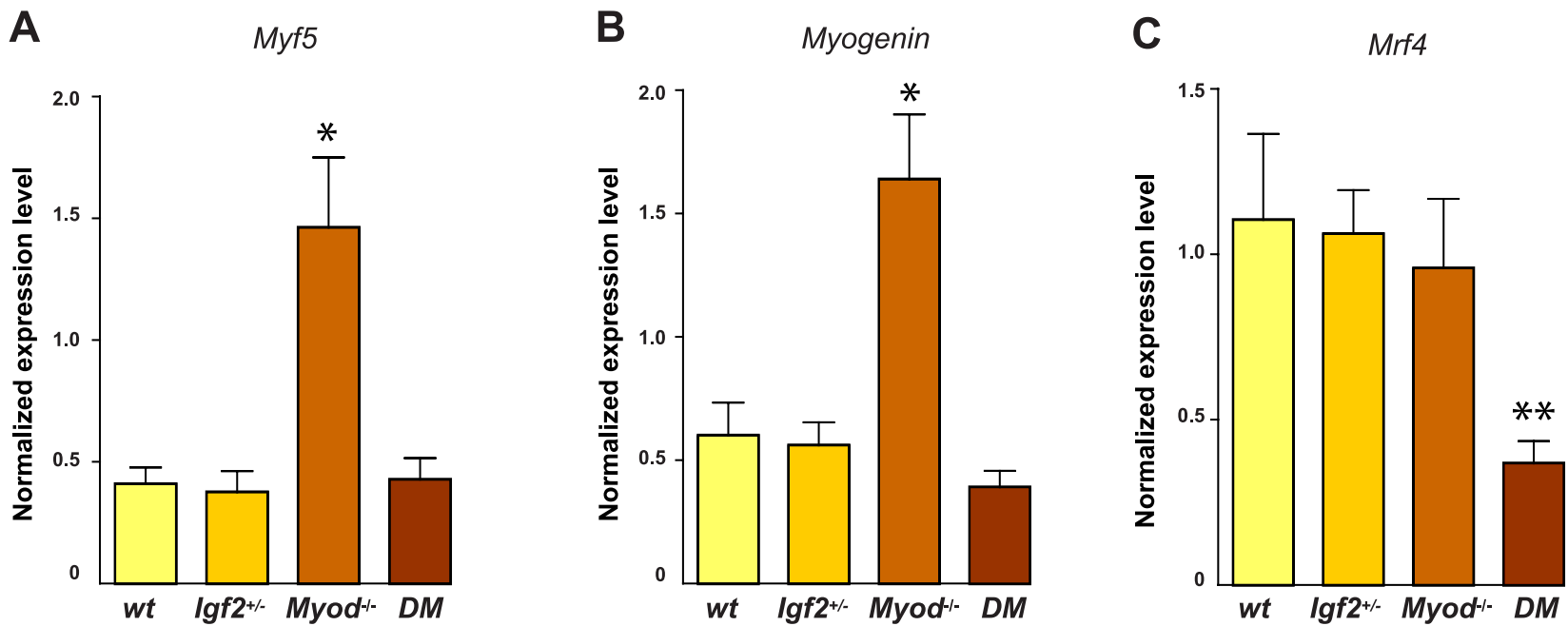

Figure 2. Expression levels of specific muscle genes. RT-qPCR was performed on E18.5 BAT from WT, SM, and DM mice $(n=5$ /genotype) using primers for the Myf5 gene $(A)$, Myogenin gene $(B)$ and Mrf4 gene $(C)$. $* P<0.05$, **P<0.01 vs. WT. 

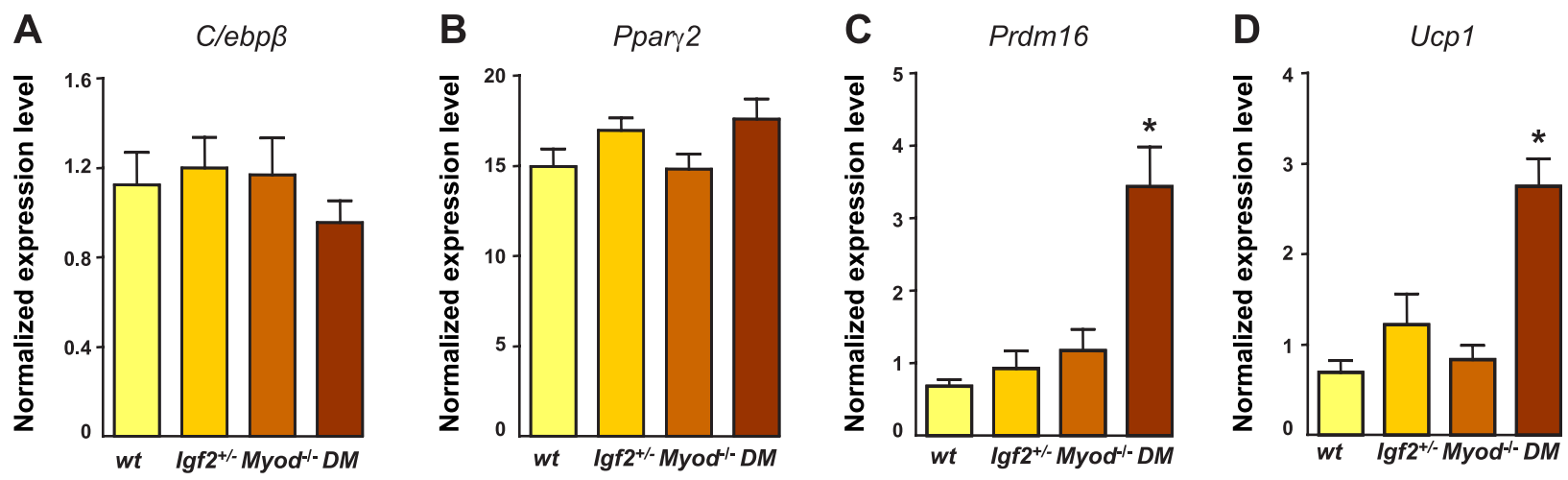

Figure 3. Expression levels of brown adipocyte genes in BAT. RT-qPCR was performed on E18.5 BAT from WT, SM, and DM mice ( $n=5$ /genotype) using primers for the $C / e b p \beta$ gene $(A), \operatorname{Ppar\gamma } 2$ gene $(B)$, Prdm 16 gene $(C)$, and $U c p 1$ gene $(D)$. $* P<0.05$ vs. WT.

the Myod transcript level in the presence of si-Myod (Fig. 4B) was observed. Interestingly, Myod and Igf2 expressions are not modified in the absence of each other. This absence of compensation mirrors the in vivo situation.

As shown in Fig. $4 C, D$, Myod or $I g f 2$ gene inactivation alone did not significantly modify T37i cell differentiation programming, as evidenced by quantification of Oil Red O staining compared with that of scrambled siRNA-treated cells. In sharp contrast, the combination of Myod and Igf2 siRNA led to a drastic acceleration of brown adipocyte differentiation, with marked lipid accumulation as early as d 5 after exposure to the induction cocktail. We next quantified gene expression of early and late adipocyte markers along with the differentiation process of T37i cells transfected with either scramble siRNA, Myod, or Igf2 siRNA, or both siRNAs (Fig. 5). After 1 $\mathrm{d}$ of differentiation (Fig. 5, D1), a significant increase in the expression of early genes, such as C/ebp $\beta$, Ppary 2, and Prdm16, was observed in double-knockdown T37i cells, consistent with a premature adipocyte commitment. Accordingly, $4 \mathrm{~d}$ later (Fig. 5, D4), Prdm16 and Ucp1 expression was markedly enhanced in double-knockdown T37i cells compared with that in controls, indicating that simultaneous lack of MYOD and IGF2 promotes early brown adipogenesis. These results strongly support the in vivo observations. Taken together, these findings provide evidence for the involvement of both Myod and $I g f 2$
Figure 4. Knockdown of Myod and Igf2 enhances brown adipocyte differentiation in vitro. $A, B)$ Efficiency of knockdown was evaluated by RT-qPCR performed on 4 samples from scramble (Scr), si-Igf2, si-Myod, and si-Igf2 si-Myod T37i cells after $1 \mathrm{~d}$ of differentiation. Expression of the $\operatorname{Ig} f 2$ gene $(A)$ and Myod gene (B) was analyzed. C) Adipocyte differentiation was evaluated by Oil Red $\mathrm{O}$ staining on Scr, si-Igf2, si-Myod, and si-Igf2 si-Myod T37i cells after $5 \mathrm{~d}$ of differentiation ( $n=4 /$ cell type). $D$ ) Optical density was measured at $520 \mathrm{~nm}$ and is represented as a graph. $* P<0.05, * * P<0.01$ vs. Scr.
A
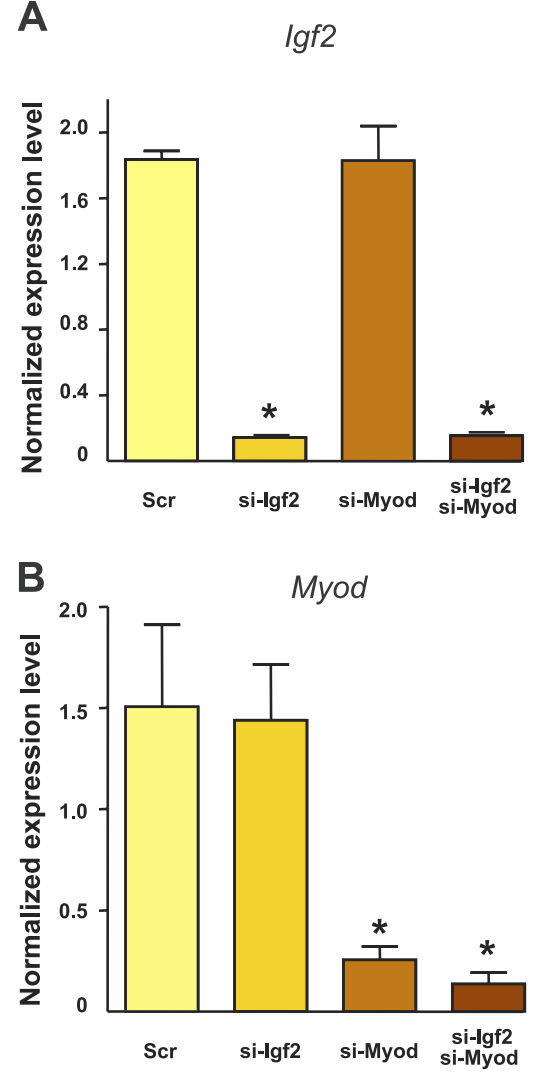

C

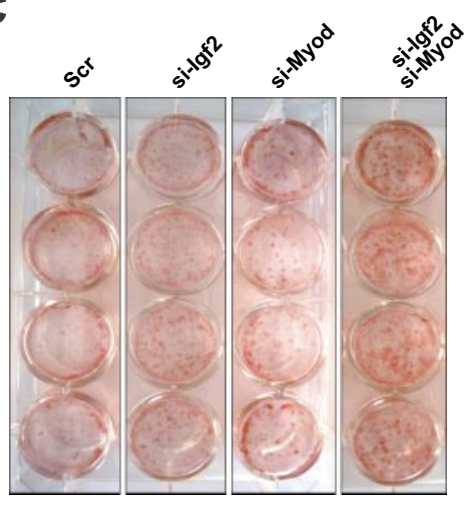

D

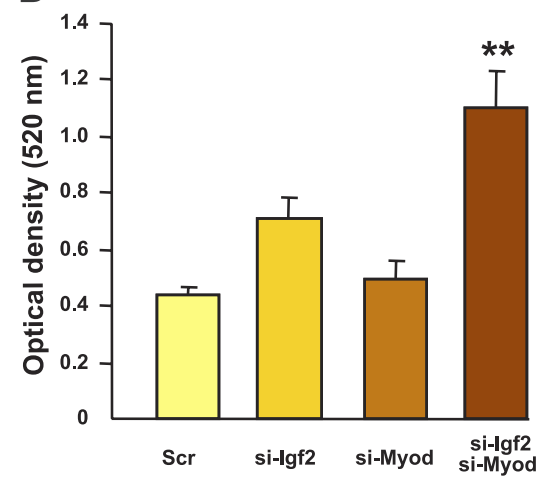



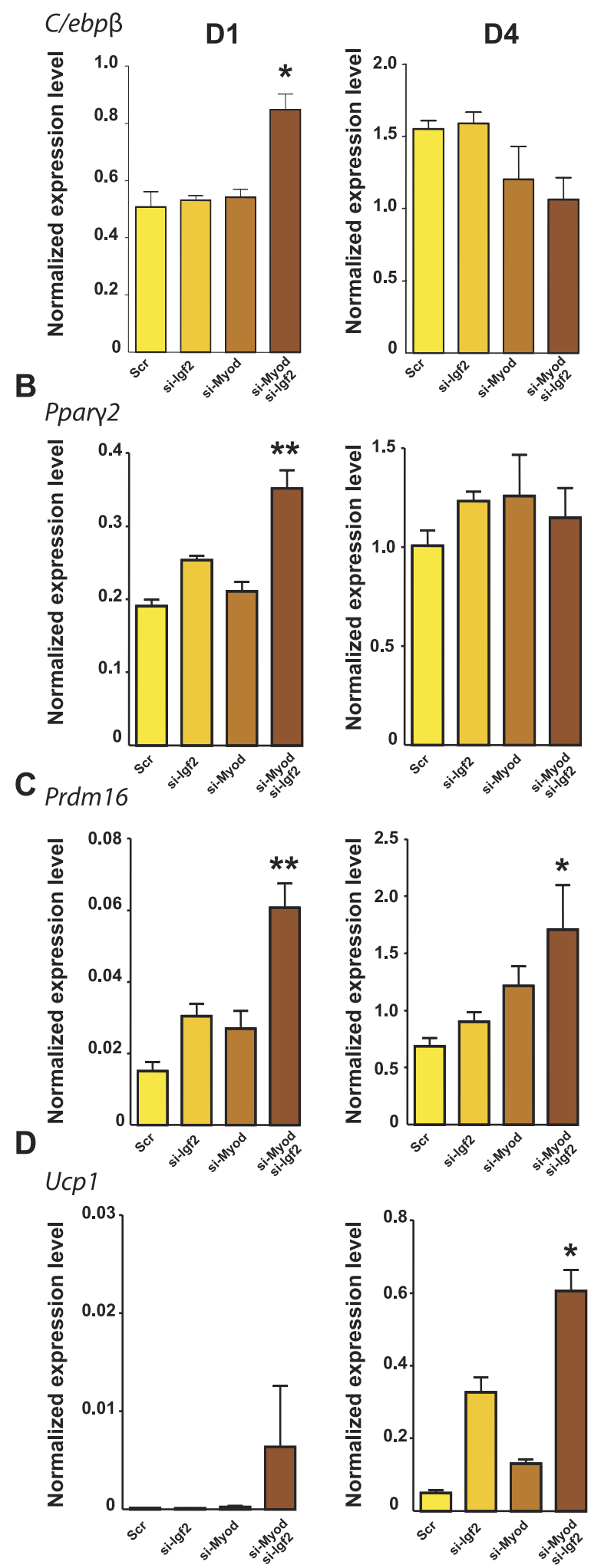

Figure 5. Knockdown of Myod and Igf2 leads to early expression of brown adipocyte genes. RT-qPCR was performed on 4 samples from scramble (Scr), si-Igf2, si-Myod, and si-Igf2 si-Myod T37i cells after 1 and $4 \mathrm{~d}$ of differentiation. Expression of the $C / \operatorname{ebp} \beta$ gene $(A)$, Ppary 2 gene $(B)$, Prdm16 gene $(C)$, and $U c p 1$ gene $(D)$ was analyzed. $* P<0.05, * * P<0.01$ vs. Scr. signaling pathways in the regulatory mechanisms governing brown adipocyte differentiation.

\section{DISCUSSION}

Increasing evidence suggests the existence of a developmental switch between myogenic and adipogenic commitment. Until recently, brown and white fat adipocytes were thought to be derived from the same precursor cell. There is now clear evidence that brown fat adipocytes arise from a separate and distinct population of progenitor cells $(4,7)$. Interestingly, this progenitor population gives rise to both myocytes and brown adipocytes, originating from a common Myf5expressing precursor. The relationship between myogenic and adipogenic commitment was evidenced many years ago by phenotypes observed in mouse mutants invalidated for the MRFs. Myod and Myf5 gene invalidation leads to a loss of muscle development replaced with adipose tissue (21). Myogenin gene invalidation results in nonviable embryos in which a large BAT depot was observed compared with that in control embryos (22).

Preadipocytes express these MRFs, such as MYF5, MYOD, and MYOGENIN, which are down-regulated on differentiation into adipocytes (23). The PRDM16 transcription factor is thought to be the key factor for adipogenesis because its expression in myogenic precursor cells induces their transformation into brown adipocytes. PRDM16 has been proposed as the regulator of the brown adipocyte fate by inhibiting expression of the MRFs and activating specific brown fat genes (13). How important is it to control the expression of myogenic factors to induce the brown fat pathway?

By investigating the effect of the two myogenic factors IGF2 and MYOD in vivo, we have been able to show their major role in controlling BAT development. Our study has revealed that newborn mice lacking both $\operatorname{Igf2}$ and Myod genes display an unexpected hypertrophy of BAT compared with that in WT and SM newborns, although $\operatorname{Igf2^{+/-}}$ mice already display a slight increase in BAT mass. The combined expression of these two genes therefore appears to play a major role in the control of the commitment toward brown adipogenesis.

Cell proliferation is strongly increased in DM BAT as shown by the Ki67 index. The presence of markers such as PPAR $\gamma 2$ and $\mathrm{C} / \mathrm{EBP} \beta$ indicates that this hypertrophic mass is of adipogenic origin and the high level of UCP1 confirms its brown fat origin. We propose that Igf 2 and Myod play an important role in controlling the development of BAT by reducing cell proliferation. Whether the observed enlargement of DM BAT is due to recruitment of new cells or expansion of preexisting progenitors would require analysis of earlier embryonic stages. However, because the levels of $M y f 5$, considered as a marker of the mesenchymal progenitors at the origin of brown adipocytes $(12,14)$, are similar in WT and DM BAT, expansion of preexisting progenitors is the most likely hypothesis.

Because of the proposed function of the Prdm16 gene in controlling brown adipocyte fate, we investigated the level of expression of this gene in $\mathrm{WT}, \mathrm{SM}$, and $\mathrm{DM}$ 
BAT. Its strong increase in expression in DM newborns suggests that this gene is under the control of both $I g f 2$ and Myod genes. Interestingly, only the combination of the two factors leads to this increased expression. Because the SMs do not display this strong hypertrophy of BAT nor increased expression of Prdm16, it can be concluded that IGF2 and MYOD act according to parallel independent pathways to control BAT size.

Based on published chromatin immunoprecipitation sequencing data (24), we searched for MYOD binding sites but found no direct binding either on the promoter or on the gene body of Prdm16. These data were available in myotubes in which $\operatorname{Prdm} 16$ expression is repressed. We cannot, however, exclude either an indirect repressive effect of MYOD or binding on a long-range regulatory element of $\operatorname{Prdm} 16$ in adipocytes.

Interestingly, whereas a general decrease in expression of all MRFs was observed in differentiating adipocytes, our data in Myod $^{-1-}$ BAT now suggest that the reduction in expression of Myf5 and Myogenin are under the control of MYOD. Furthermore, whereas Myf5 and Myogenin expression levels are barely affected in DM BAT, Mrf4 expression seems to be strongly reduced. Whether this reduction is a cause or a consequence of BAT hypertrophy remains unknown. This leads to two possibilities: either Mrf4 expression is tightly regulated by the combined expression of $I g f 2$ and Myod, or Mrf4 is under the direct control of the Prdm16 gene. Nevertheless, both Mrf4 and Prdm16 are involved in the control of BAT determination. This finding also emphasizes the need to repress $\mathrm{Mrf4}$ gene expression to engage in adipogenesis (Fig. 6).
To our knowledge, very little is known about the influence of Igf2 on BAT development. IGF2 is a fetal growth factor, which is repressed after birth and replaced by IGF1 $(25,26)$. A mouse model in which Igf2 expression is reduced but not absent displayed decreased BAT development (27). We must therefore assume that other factors, such as IGF1, take over at birth and participate in BAT development.

Interestingly, it was recently shown that insulin receptor substrate-1 (IRS1) is involved in the maturation of adipocytes, implicating the AKT/PI3K pathway (28). IRS1 is a downstream target of IGF1/INS1 receptors. Because these receptors also bind IGF2, this could explain how IGF2 is involved in adipogenesis during the fetal period and how it could act as an upstream regulator of this AKT/PI3K pathway. Because IGF2 plays a dual role in proliferation and differentiation, it was not clear whether the BAT hypertrophy was due only to increased proliferation or also to altered differentiation. We therefore set up an in vitro model to follow brown adipocyte differentiation in preadipocyte cells. Interestingly, Myod and Igf2 knockdown by siRNA shows a phenotype similar to that of the in vivo model. Si-Igf2 and si-Myod preadipocytes present a higher number of lipidic droplets after $5 \mathrm{~d}$ of culture compared with scramble and single siRNA samples, as well as an increase in $\operatorname{Prdm} 16$ and $U c p 1$ expression. Furthermore, in vitro differentiation revealed an earlier expression of differentiation genes such as $C / e b p \beta$ and Ppary 2 only in the double-siRNA-treated cells.

In summary, our in vivo and in vitro studies have revealed a combined role of Myod and Igf2 genes during
Figure 6. Model of brown adipocyte pathway under the control of the Prdm16 regulator. MYOD and IGF2 act coordinately to repress PRDM16 in BAT formation and activate the skeletal muscle pathway.

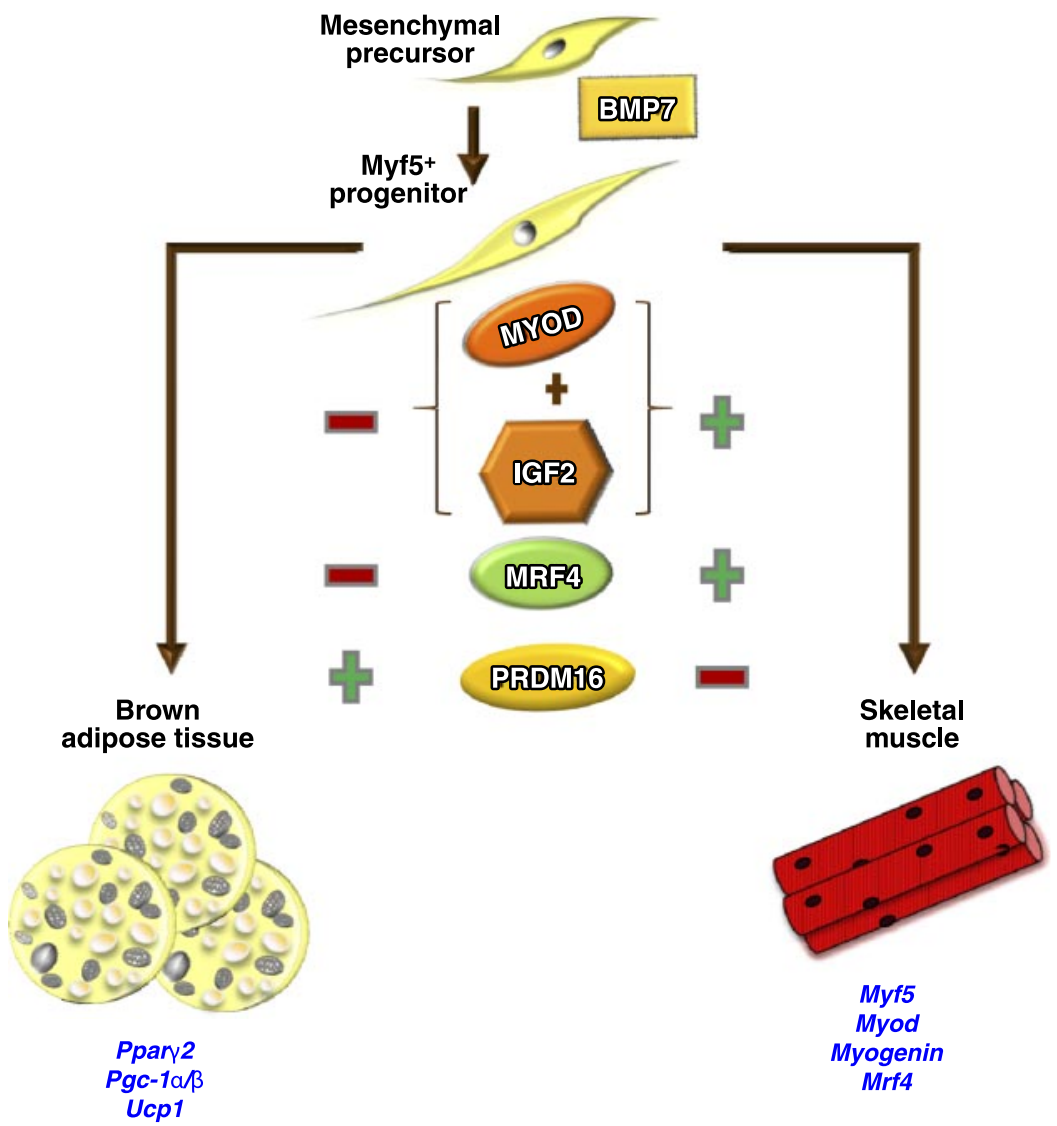


brown adipocyte proliferation and differentiation. These two genes act coordinately to repress BAT development as shown both in the in vivo DM model and in the in vitro knockdown cell culture system. Because the expression of the Prdm16 "brown master gene" is strongly up-regulated in the absence of these two genes, we propose that MYOD and IGF2 act as upstream regulators of PRDM16 to control proliferation of BAT during development.

BAT has been shown to regulate energy balance and to play a role in fighting against obesity in rodents. It may also play a significant role in the physiology of human adults. Better knowledge of the brown lineage is therefore an essential step in the control of obesity. Investigating mechanisms that control the timing and specificity of Prdm16 expression during development is therefore an important health issue.

The authors are grateful to Elizabeth J. Robertson (University of Oxford, Oxford, UK) and Argiris Efstratiadis (Columbia University, New York, NY, USA) for the $I g f 2^{-/-}$mice and to Michael A. Rudnicki (Ottawa Health Research Institute, Ottawa, ON, Canada)for the $\mathrm{Myod}^{-/-}$mice. The authors are grateful to Margaret Buckingham for critical reading of the article. This work was supported by funding from the Association Française contre les Myopathies and the ANR Epinet Project to L.D. and by fellowships from the Ministère de la Recherche et de l'Enseignement Supérieur and the Fondation de la Recherche Médicale to M.B.

\section{REFERENCES}

1. Kajimura, S., Seale, P., and Spiegelman, B. M. (2010) Transcriptional control of brown fat development. Cell Metab. 11, 257-262

2. Gupta, R. K., Arany, Z., Seale, P., Mepani, R. J., Ye, L., Conroe, H. M., Roby, Y. A., Kulaga, H., Reed, R. R., and Spiegelman, B. M. (2010) Transcriptional control of preadipocyte determination by Zfp423. Nature 464, 619-623

3. Cannon, B., and Nedergaard, J. (2004) Brown adipose tissue: function and physiological significance. Physiol. Rev. 84, 277-359

4. Gesta, S., Tseng, Y., and Kahn, C. (2007) Developmental origin of fat: tracking obesity to its source. Cell 131, 242-256

5. Cypess, A., Lehman, S., Williams, G., Tal, I., Rodman, D., Goldfine, A., Kuo, F., Palmer, E., Tseng, Y., Doria, A., Kolodny, G., and Kahn, C. (2009) Identification and importance of brown adipose tissue in adult humans. N. Engl. J. Med. 360, 1509-1517

6. Nedergaard, J., Bengtsson, T., and Cannon, B. (2007) Unexpected evidence for active brown adipose tissue in adult humans. Am. J. Physiol. Endocrinol. Metab. 293, E444-E452

7. Timmons, J. A., Wennmalm, K., Larsson, O., Walden, T. B., Lassmann, T., Petrovic, N., Hamilton, D. L., Gimeno, R. E., Wahlestedt, C., Baar, K., Nedergaard, J., and Cannon, B. (2007) Myogenic gene expression signature establishes that brown and white adipocytes originate from distinct cell lineages. Proc. Natl. Acad. Sci. U. S. A. 104, 4401-4406

8. Whittle, A. J., Lopez, M., and Vidal-Puig, A. (2011) Using brown adipose tissue to treat obesity-the central issue. Trends Mol. Med. 17, 405-411

9. Atit, R., Sgaier, S., Mohamed, O., Taketo, M., Dufort, D., Joyner, A., Niswander, L., and Conlon, R. (2006) $\beta$-Catenin activation is necessary and sufficient to specify the dorsal dermal fate in the mouse. Dev. Biol. 296, 164-176

10. Petrovic, N., Walden, T. B., Shabalina, I. G., Timmons, J. A., Cannon, B., and Nedergaard, J. (2010) Chronic peroxisome proliferator-activated receptor gamma (PPAR $\gamma)$ activation of epididymally derived white adipocyte cultures reveals a population of thermogenically competent, UCP1-containing adi- pocytes molecularly distinct from classic brown adipocytes. $J$. Biol. Chem. 285, 7153-7164

11. Walden, T., Timmons, J., Keller, P., Nedergaard, J., and Cannon, B. (2009) Distinct expression of muscle-specific microRNAs (myomirs) in brown adipocytes. J. Cell. Physiol. 218, 444-449

12. Seale, P., Kajimura, S., Yang, W., Chin, S., Rohas, L., Uldry, M., Tavernier, G., Langin, D., and Spiegelman, B. (2007) Transcriptional control of brown fat determination by PRDM16. Cell Metab. 6, 38-54

13. Seale, P., Bjork, B., Yang, W., Kajimura, S., Chin, S., Kuang, S., Scime, A., Devarakonda, S., Conroe, H. M., Erdjument-Bromage, H., Tempst, P., Rudnicki, M. A., Beier, D. R., and Spiegelman, B. M. (2008) PRDM16 controls a brown fat/skeletal muscle switch. Nature 454, 961-967

14. Fruhbeck, G., Sesma, P., and Burrell, M. A. (2009) PRDM16: the interconvertible adipo-myocyte switch. Trends Cell Biol. 19, 141146

15. Enerbäck, S., Jacobsson, A., Simpson, E., Guerra, C., Yamashita, H., Harper, M., and Kozak, L. (1997) Mice lacking mitochondrial uncoupling protein are cold-sensitive but not obese. Nature 387, 90-94

16. Zennaro, M. C., Le Menuet, D., Viengchareun, S., Walker, F., Ricquier, D., and Lombes, M. (1998) Hibernoma development in transgenic mice identifies brown adipose tissue as a novel target of aldosterone action. J. Clin. Invest. 101, 1254-1260

17. Vandesompele, J., De Preter, K., Pattyn, F., Poppe, B., Van Roy, N., De Paepe, A., and Speleman, F. (2002) Accurate normalization of real-time quantitative RT-PCR data by geometric averaging of multiple internal control genes. Genome Biol. 3, RESEARCH0034

18. DeChiara, T. M., Efstratiadis, A., and Robertson, E. J. (1990) A growth deficiency phenotype in heterozygous mice carrying an Insulin-like growth factor II gene disrupted by gene targeting. Nature 345, 78-80

19. Kablar, B., Asakura, A., Krastel, K., Ying, C., May, L. L., Goldhamer, D. J., and Rudnicki, M. A. (1998) MyoD and Myf-5 define the specification of musculature of distinct embryonic origin. Biochem. Cell Biol. 76, 1079-1091

20. Kablar, B., Krastel, K., Ying, C., Asakura, A., Tapscott, S. J., and Rudnicki, M. A. (1997) MyoD and Myf-5 differentially regulate the development of limb versus trunk skeletal muscle. Development 124, 4729-4738

21. Rudnicki, M. A., Schnegelsberg, P. N., Stead, R. H., Braun, T., Arnold, H. H., and Jaenisch, R. (1993) MyoD or Myf-5 is required for the formation of skeletal muscle. Cell 75, 13511359

22. Hasty, P., Bradley, A., Morris, J. H., Edmondson, D. G., Venuti, J. M., Olson, E. N., and Klein, W. H. (1993) Muscle deficiency and neonatal death in mice with a targeted mutation in the myogenin gene. Nature 364, 501-506

23. Hu, E., Tontonoz, P., and Spiegelman, B. M. (1995) Transdifferentiation of myoblasts by the adipogenic transcription factors PPAR $\gamma$ and C/EBP $\alpha$. Proc. Natl. Acad. Sci. U. S. A. 92, 9856-9860

24. Mullen, A. C., Orlando, D. A., Newman, J. J., Loven, J., Kumar, R. M., Bilodeau, S., Reddy, J., Guenther, M. G., DeKoter, R. P., and Young, R. A. (2011) Master transcription factors determine cell-type-specific responses to TGF- $\beta$ signaling. Cell 147, 565-576

25. Baker, J., Liu, J. P., Robertson, E. J., and Efstratiadis, A. (1993) Role of insulin-like growth factors in embryonic and postnatal growth. Cell 75, 73-82

26. Foulstone, E., Prince, S., Zaccheo, O., Burns, J., Harper, J., Jacobs, C., Church, D., and Hassan, A. (2005) Insulin-like growth factor ligands, receptors and binding proteins in cancer. J. Pathol. 205, 145-153

27. Viengchareun, S., Servel, N., Feve, B., Freemark, M., Lombes, M., and Binart, N. (2008) Prolactin receptor signaling is essential for perinatal brown adipocyte function: a role for insulinlike growth factor-2. PLoS One 3, e1535

28. Cypess, A. M., Zhang, H., Schulz, T. J., Huang, T. L., Espinoza, D. O., Kristiansen, K., Unterman, T. G., and Tseng, Y. H. (2011) Insulin/IGF-I regulation of necdin and brown adipocyte differentiation via CREB- and FoxO1-associated pathways. Endocrinology 152, 3680-3689

Received for publication March 21, 2012. Accepted for publication July 24, 2012. 